\title{
Three-Dimensional Mathematical Investigation of Dynamic and Hydrostatic Pressure Distributions on Planing Hulls
}

\author{
Parviz Ghadimi, Sasan Tavakoli, Abbas Dashtimanesh, and Seyed Reza Djeddi \\ Department of Marine Technology, Amirkabir University of Technology, Hafez Avenue, No. 424, P.O. Box 15875-4413, Tehran, Iran \\ Correspondence should be addressed to Parviz Ghadimi; pghadimi@aut.ac.ir
}

Received 15 May 2013; Accepted 27 July 2013

Academic Editor: Jia-Jang Wu

Copyright ( 2013 Parviz Ghadimi et al. This is an open access article distributed under the Creative Commons Attribution License, which permits unrestricted use, distribution, and reproduction in any medium, provided the original work is properly cited.

\begin{abstract}
A mathematical model is utilized in order to calculate three-dimensional pressure distributions on planing hulls. This type of modeling is able to determine the hydrodynamic and hydrostatic pressures acting on the bottom of these hulls. As a result, the total 3-dimensional pressure exerted on the planing hull as a sum of hydrostatic and hydrodynamic pressures can be evaluated. Empirical equations introduced in previous works have been used as the fundamentals for the present mathematical modeling method. The obtained results are compared against available experimental results and results of empirical equations in order to validate the proposed method. The outcome of the $R$-squared tests conducted on these comparisons shows favorable accuracy of the results. After evaluation of hydrodynamic pressure, the effects of trim and deadrise angles and wetted length on the 3-dimensional pressure distribution are analyzed. Finally, the total pressure on planing hull and the effect of velocity coefficients are studied.
\end{abstract}

\section{Introduction}

Determining the exerted pressure on the planing hulls is essential to the study of their dynamics. By computing this pressure, it becomes possible to calculate the lift force, center of pressure, vessel's dynamic, and water spray. Complexities concerned with 3-dimensional pressure distributions have made their direct calculation improbable, if not impossible. Therefore, a common approach is to first measure the pressure distribution using 2-dimensional longitudinal and transverse solutions which can be later used for calculation of 3-dimensional pressure distribution acting on the planing hull. Additionally, experimental methods can be used for calculation of pressure distribution in this type of vessel. Among these experimental works, results of Kapryan and Boyd [1] and Smiley [2,3] are of high importance. On the other hand, Wagner [4] used analytical methods to evaluate pressure distribution over a wedge in a water-entry problem which is identical to the pressure distribution acting on an infinite planing plane.

It was proved in Smiley's experiments [3] that the longitudinal pressure distribution on the side sections of the center line is less than that on the other sections. Based on these results, empirical equations for evaluation of longitudinal pressure distribution were proposed. Later, Kapryan and Boyd [1] showed in their experimental studies that pressure on planing hulls will be reduced with an increase in the deadrise angle.

With the advances in computational and computer resources, mathematical modeling methods for the analyses of planing vessels were introduced. These methods take advantage of high speed and high efficiency of the computational tools and bring about higher accuracy. One of the most well-known mathematical models is the method proposed by Savitsky [5]. The basis for this modeling is the use of experimental results which lead to empirical equations that can be implemented for mathematical modeling in planing hulls in order to evaluate the lift force, center of pressure, and resistance.

Numerical modeling of planing vessels has also gained attention in the past decades. Although this method is time consuming and expensive, many works can be found in the literature taking this approach. A famous work in this field is the numerical study of Wellicome and Jahangeer [6] in which the 3-dimensional pressure distribution over the planing hull was evaluated using computational techniques. 


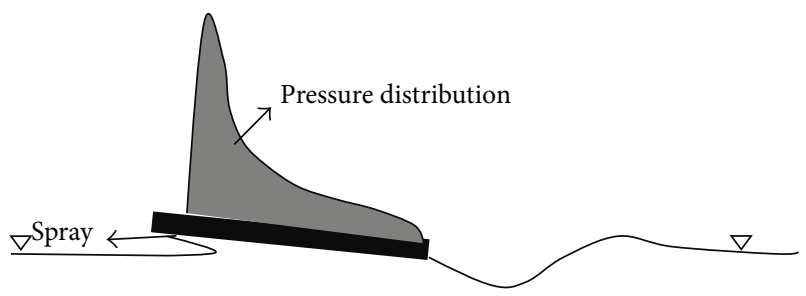

(a)

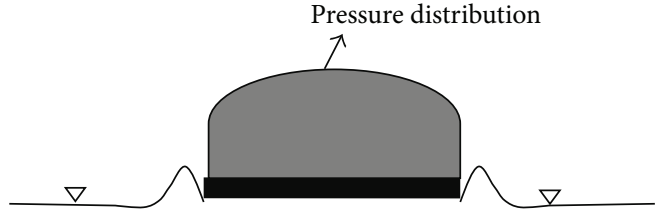

(b)

FIgURE 1: Longitudinal (a) and transverse (b) pressure distribution on planing hulls [10].

Also in a recent attempt, Ghadimi et al. [7] used the method of Smoothed-particle hydrodynamics (SPH) in order to study flow around the planing plate and consequently find pressure distribution over this surface.

The initial modeling method of Savitsky [5] was later modified and improved by Savitsky et al. [8] by implementing whisker spray and the resulting wetted area. In another work, Morabito [9] studied the water spray and pressure distribution over planing hulls. As a result of his studies, a set of empirical equations was introduced for calculation of pressure distribution on planing hulls. In the present study, empirical equations of Morabito [9] are used as the basis of the mathematical model introduced for evaluation of pressure distribution of a plning hull.

\section{Mathematical Formulation}

One of the simplest techniques used for evaluation of planing vessels' dynamics is the planing plate model. Sottorf [10] studied the pressure distribution on a planing plate in both longitudinal and transverse directions. Therefore, a plot of the longitudinal and transverse pressure distribution over a planing plate was introduced by Sottorf [10], as shown in Figure 1. In the present paper, the goal is to first calculate pressures on different longitudinal sections which can later be used for 3-dimensional pressure distribution over the planing hull with consideration of transom stern effects and then calculate the pressure alleviation which occur when getting farther from the center line.

2.1. Stagnation Line and Maximum Pressure. When a planing plane is moving along the water surface, a stagnation line appears on both sides of the center line. It was shown that the maximum pressure on planing hulls occurs at the stagnation line [11]. A spray area appears in front of the stagnation line on which the spray resistance force occurs, while pressure area appears in the aft direction in which drag and lift forces exist. The stagnation line and spray and pressure areas for a planing hull are depicted in Figure 2.

Based on fluid dynamics theories, when a free flow collides with an obstacle, the maximum pressure occurs at a stagnation point. In the case of a planing hull, all the stagnation points lie on the stagnation line. Experiments by Smiley [3] proved that pressure distribution will fall on sections close to the stagnation line. Therefore, it can be

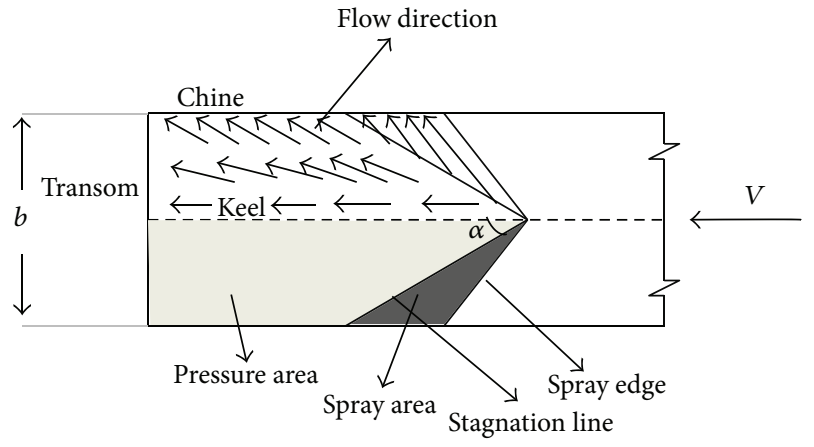

FIGURE 2: Bottom of a planing hull illustrating different sections [8].

concluded that at each section of the planing hull, the maximum pressure will occur at the stagnation line. Moreover, the pressure will also reduce along this line where at the intersection of the stagnation line and the center line, the maximum possible pressure will appear. Smiley [3] proposed the following equation for the maximum pressure acting on the planing hull:

$$
\frac{P_{\max }}{(1 / 2) \rho V^{2}}=\frac{\pi^{2} \tan ^{2} \tau}{\pi^{2} \tan ^{2} \tau+4 \tan ^{2} \beta},
$$

in which $P_{\max }$ is the maximum pressure, $\rho$ is the water density, $V$ is the advance velocity of the vessel, $\tau$ is the trim angle, and $\beta$ is the deadrise angle. Also, Morabito [9] introduced the following formula for determination of the maximum pressure:

$$
\begin{gathered}
\frac{P_{\max }}{q}=\sin ^{2} \alpha, \\
q=\frac{1}{2} \rho V^{2},
\end{gathered}
$$

where $\alpha$ is the angle between the stagnation and center lines which was defined by Savitsky [5] using (4), as in

$$
\alpha=\tan ^{-1} \frac{\pi}{2} \frac{\tan \tau}{\tan \beta} .
$$

Figure 3 shows the maximum pressure at different trim and deadrise angles.

As clearly seen in Figure 1, the pressure alleviates just after reaching its maximum value. The pressure will vanish at 


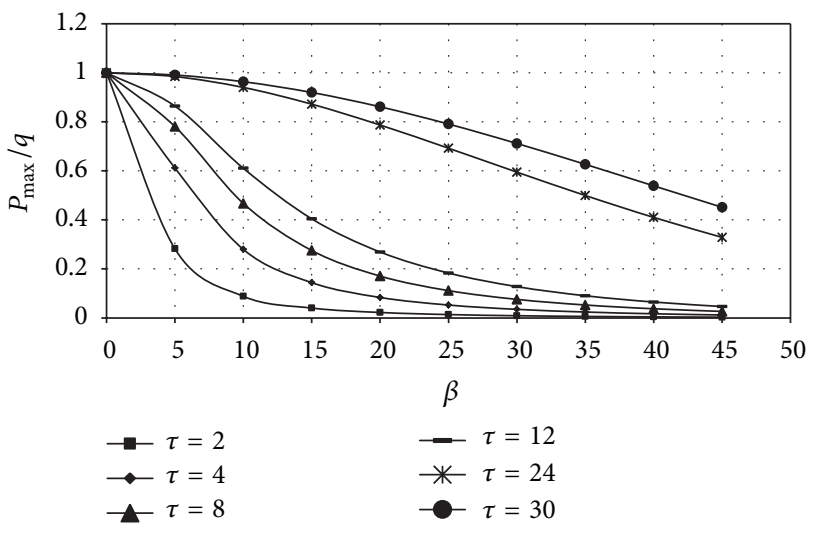

Figure 3: Maximum pressure versus deadrise angle at different trim angles using empirical equations of [9].

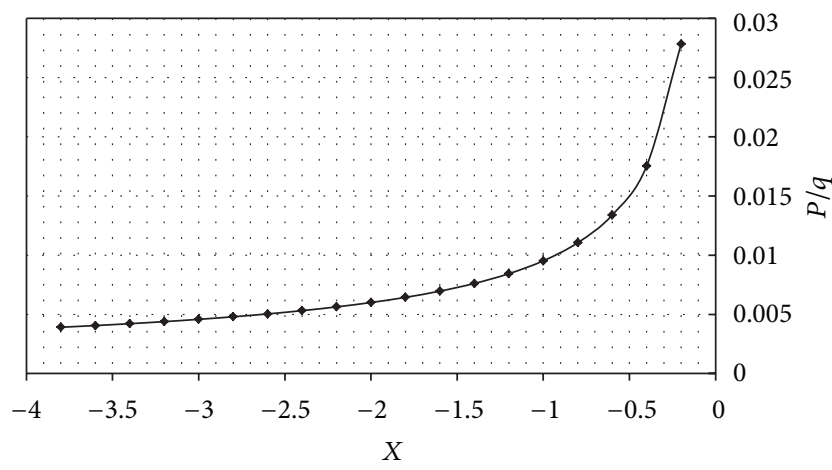

FIGURE 4: Longitudinal pressure distribution over a planing hull using (6) as introduced by Smiley [3].

the transom due to the atmospheric conditions. The pressure decrease is calculated using (5) as proposed by Smiley [3]

$$
\frac{P_{L}}{q}=0.006 \frac{\tau^{1 / 3}}{X^{2 / 3}}
$$

The previous equation can be used for the aft areas of the stagnation point. Pressure $P_{L}$ is the pressure at any point behind the stagnation line, and $X$ is the dimensionless distance between the stagnation line and the desired section which is given by (6)

$$
X=\frac{x}{b}
$$

in which $b$ is the hull's breadth. An example of the calculated pressure over the stagnation line using (6) for a planing hull with a trim angle of $4^{\circ}$ and a nondimensional wetted length of 4, is depicted in Figure 4.

Equation (6), at $X=0$, yields to infinity. Therefore, Morabito [9] proposed (7) for the maximum pressure value which vanishes at $X=0$ :

$$
\frac{P_{L}}{q}=\frac{C X^{1 / 3}}{(X+K)}
$$

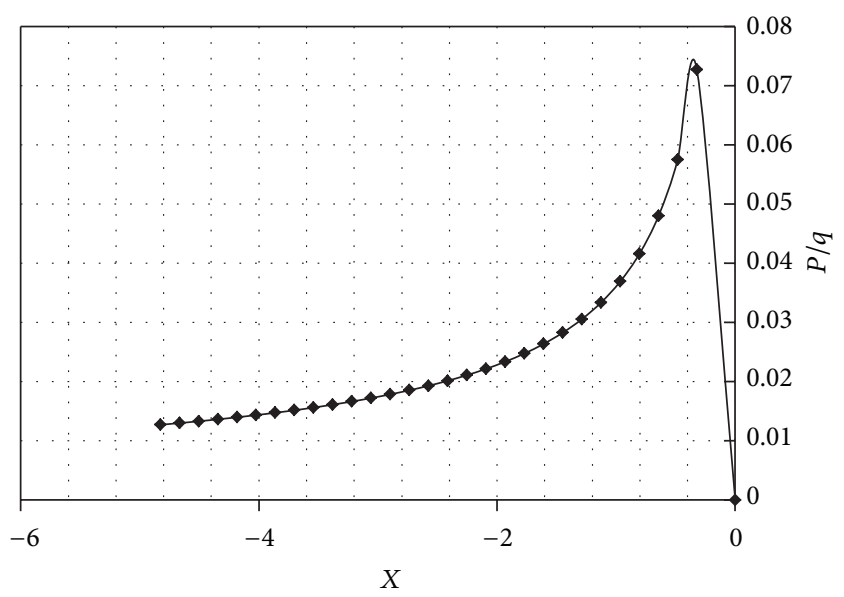

FIGURE 5: Longitudinal pressure distribution over the center line of a planing hull using (7) as introduced by Morabito [9].

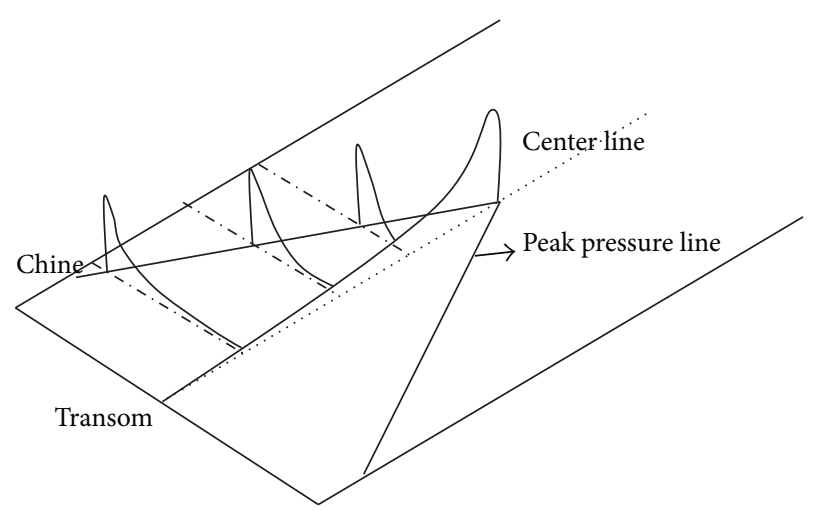

FIGURE 6: Pressure distribution over the bottom of a planing boat [3].

in which

$$
\begin{gathered}
C=0.006 \tau^{1 / 3}, \\
K=\frac{C^{1.5}}{2.588\left(P_{\max } / q\right)^{1.5}} .
\end{gathered}
$$

An example of the calculated pressure distribution using (7) for a vessel with $\tau=4, \lambda=4$, and $\beta=20$ is shown in Figure 5. As clearly seen, the pressure does not fade at the transom stern. In other words, the effect of the transom stern has not been taken into consideration.

Morabito [9] proposed a transom correction factor to longitudinal pressure distribution, $P_{T}$, in order to take into consideration the effect of the transom stern on this distribution. This factor which can be evaluated using (10) causes the longitudinal pressure distribution to start decreasing from a region close to transom (half breadth from the stern) and vanish at the transom stern. It also causes the pressure to never reach a value of unity close to the stagnation line (see Figure 6). 
Consider

$$
P_{T}=\frac{\left(\lambda_{y}-X\right)^{1.4}}{\left(\lambda_{y}-X\right)^{1.4}+0.05}
$$

Here, $\lambda_{y}$ is the distance between the stagnation line and the transom stern at the desired cross-section which can be calculated for each longitudinal section with a nondimensional transverse distance of $Y=y / b$ from the center line using the following equation:

$$
\lambda_{y}=\lambda-\frac{(Y-0.25)}{\tan \alpha}
$$

The diagram presented in Figure 5 is changed to the one shown in Figure 7 by implementation of the transom stern effect. It is clear from Figure 7 that the longitudinal pressure distribution is significantly affected, close to the transom stern.

2.2. Transverse Pressure Distribution and Longitudinal Distribution on Other Sections. As stated in the introduction, the pressure will alleviate along the transverse sections and will vanish at the chine. Based on this fact, the solution of KorvinKroukovsky [12] is used which introduces a factor for the transverse pressure distribution. This factor gives the ratio of pressure at a transverse section with fixed length to the pressure at the center line. Equation (11) is given based on the solution of Korvin-Kroukovsky [12] as follows:

$$
P_{Y}=\left[1.02-0.05(\beta+5) Y^{1.4}\right] \frac{0.5-Y}{0.51-Y} .
$$

The previous equation gives the pressure reduction based on the distance from the center line, but does not account for the pressure decrease close to the stagnation line in other sections.

Using the swept wing theory, Morabito [9] calculated the maximum pressure on each longitudinal section. He assumed the velocity vector on the bottom of the planing hull to be consisting of two components, one along the stagnation line $V_{s}$ and the other normal to the stagnation line $V_{n}$. Figure 8 depicts the bottom of the planing hull with the velocity vectors based on the method of Morabito [9].

Components of the velocity vector acting on the bottom of a planing hull are calculated using (13) as follows:

$$
\begin{aligned}
& V_{n}=V \sin \alpha, \\
& V_{s}=V \cos \alpha,
\end{aligned}
$$

in which $V$ is the advance velocity of the vessel. By considering $P_{N}$ as the dynamic pressure resulting from the velocity component normal to the stagnation line, Morabito [9] introduced the ratio of stagnation pressure $P_{Y \text { Stag }}$ to the dynamic pressure $P_{N}$ at each longitudinal section using the semiempirical equation (14). By multiplying (2) by this ratio, maximum pressure at each longitudinal section $\left(P_{\max } / q\right)_{Y}$, which is the pressure at the stagnation line over that section, is obtained as given in (15). This ratio has a value lower than

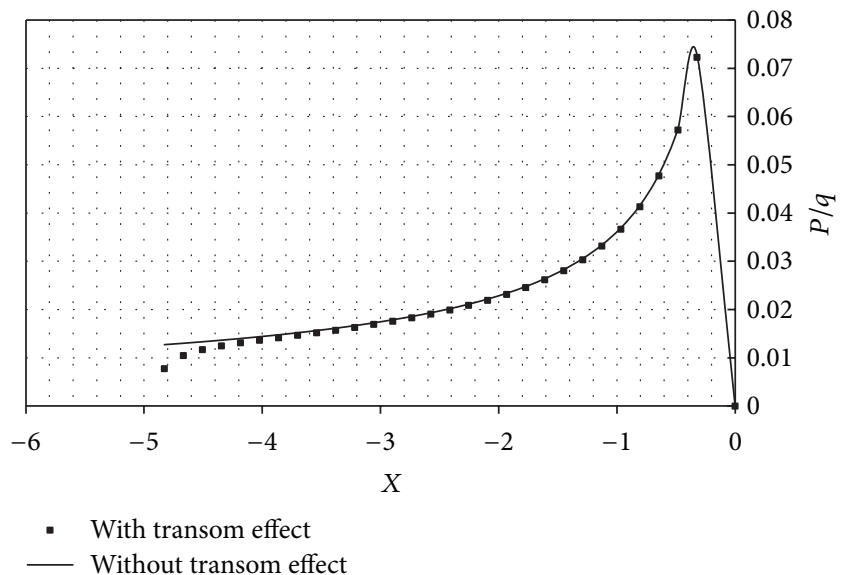

FIGURE 7: Effect of the transom correction factor on the longitudinal pressure distribution along the center line.

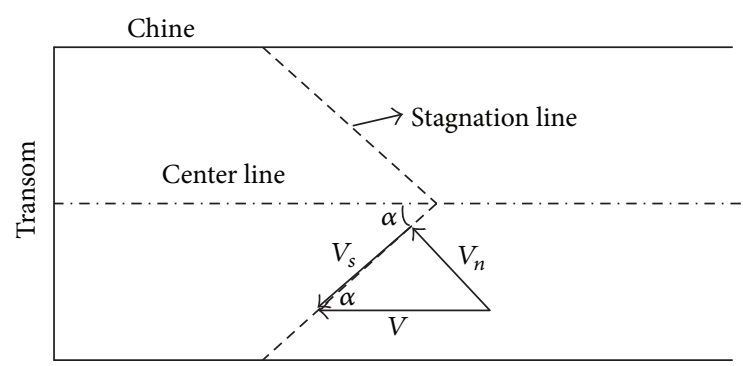

FIGURE 8: Components of the velocity vector for a planing hull [9].

the unity for all longitudinal sections except for the center line and will decrease with the distance from the keel line. After multiplication, the pressure at the stagnation line will also alleviate with the distance from the center line and finally vanish at the chine. At $Y=0$, the ratio yields to unity and gives the maximum dynamic pressure acting on the bottom of the planing hull as in

$$
\begin{gathered}
\frac{P_{Y \text { Stag }}}{P_{N}}=\left[1.02-0.25 Y^{1.4}\right] \frac{0.5-Y}{0.51-Y}, \\
\frac{P_{\max }}{q_{Y}}=\frac{P_{Y \text { Stag }}}{P_{N}} \sin ^{2} \alpha .
\end{gathered}
$$

When the maximum pressure at each longitudinal section is calculated using (14) and (15), the only remaining task is to evaluate the longitudinal pressure distribution for the desired section. Therefore, (7) is used for this task with the exception that coefficients $C$ and $K$ will now be modified with the ones that take into account the effect of distance from the stagnation line. The modified coefficients are calculated using (16) and (17) instead of (8) and (9). Finally, the effect of the transom stern on the pressure distribution at the desired section is taken into consideration:

$$
\begin{gathered}
C=0.006 P_{Y} \tau^{1 / 3}, \\
K=\frac{C^{1.5}}{2.588\left(\left(P_{\max } / q\right)_{Y}\right)^{1.5}} .
\end{gathered}
$$




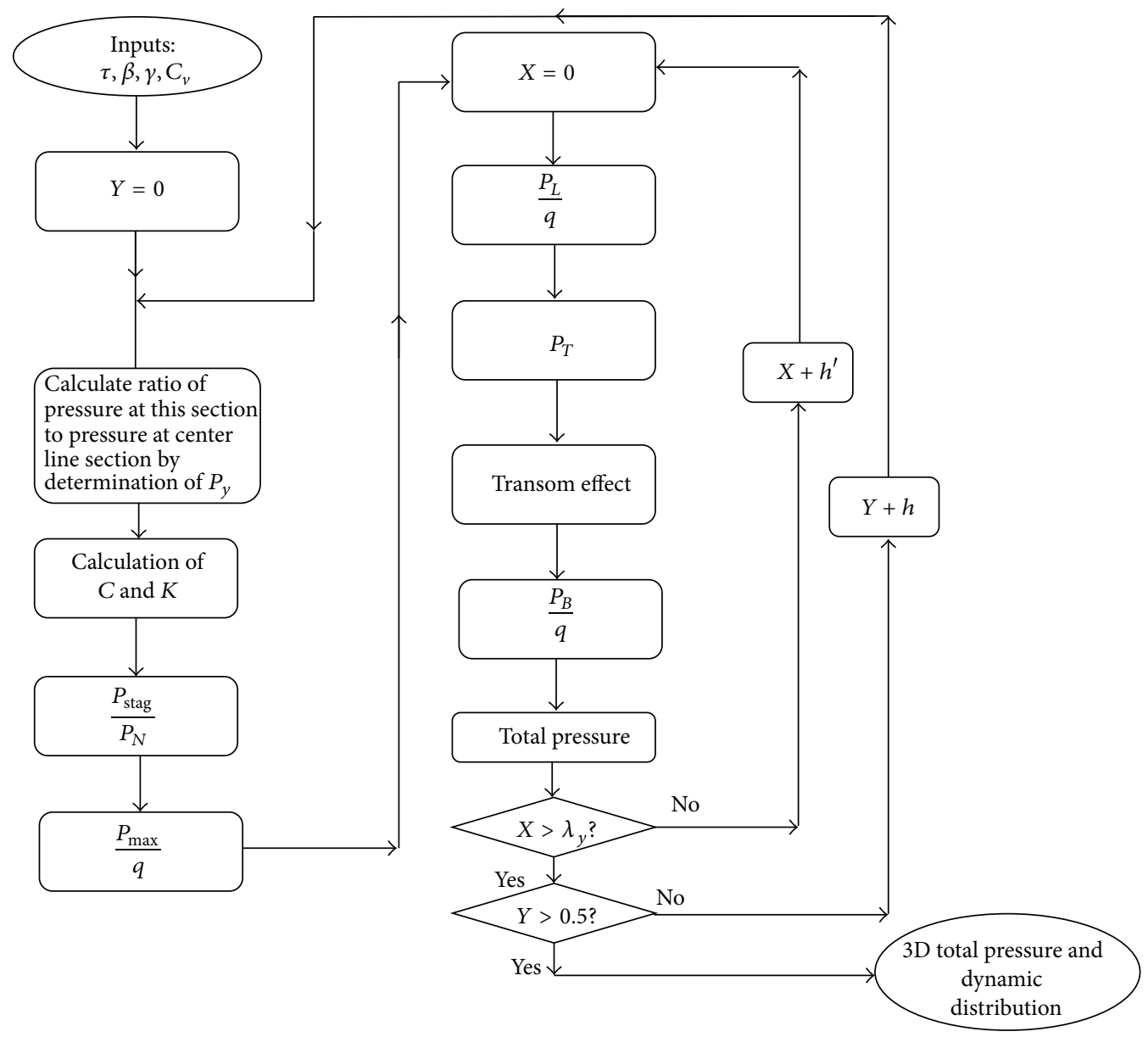

FIGURE 9: Flowchart of the present algorithm in order to evaluate the pressure distribution over planing hulls.

Clearly, when $Y=0, P_{Y}$ in (16) will be equal to 1 , and therefore, (16) and (17) will be identical to (8) and (9).

2.3. Hydrostatic and Total Pressure. Based on the theories of fluid mechanics and buoyancy, the force that is exerted by the fluid on the floating body is equal to the volume that the body displaces [13]. On the contrary, in the case of planing hulls, this value is less than that of the displaced volume $[5,14]$. Shuford [14] assumed the buoyancy force to be equal to the half of the displaced volume and Savitsky [5] took into account the effect of the wetted length for the calculation of this force. The main reason for the decrease of the buoyancy force can be sought in the fact that hydrostatic pressure distribution $P_{B}$ on the planing hull is altered. It is possible to take into account the effect of transom stern and breadth on the hydrostatic pressure distribution in a way that hydrostatic pressure at any given point on the planing hull body is calculated by the multiplication of these two factors. Equation (18) shows this simplification,

$$
\frac{P_{B}}{q}=\frac{\rho g H(X, Y)}{q} P_{T} P_{Y} .
$$

Here, $g$ is the gravitational accelerations and $H$ is the depth of the given point. Morabito [9] proposed (19) based on the previous formula where $\alpha_{W}$ is the angle between the center line and the calm water line which can be calculated using (20). The velocity coefficient $\left(C_{V}\right)$ in (19) is given by (21) and clearly, the velocity increase will cause the hydrostatic pressure to decrease

$$
\begin{gathered}
\frac{P_{B}}{q}=\frac{2 P_{T} P_{Y} \sin \tau}{C_{V}^{2}}\left(X+Y\left(\frac{1}{\tan \alpha}-\frac{1}{\tan \alpha_{W}}\right)\right), \\
\alpha_{W}=\tan ^{-1}\left(\frac{\tan \tau}{\tan \beta}\right), \\
C_{V}=\frac{V}{\sqrt{g b}} .
\end{gathered}
$$

The total pressure acting on the planing hull as a sum of dynamic and hydrostatic pressures is given by (22) as follows:

$$
\frac{P_{\text {Total }}}{q}=\frac{P_{L}}{q}+\frac{P_{B}}{q} .
$$

2.4. Modeling Method. The equations introduced thus far are used for 3-dimensional modeling in a way that the bottom of the planing hull is divided into a set of gridlines. At each longitudinal section with a fixed breadth, the longitudinal 
TABLE 1: $R$-squared values for demonstrating the accuracy of the predicted dynamic pressure distribution by the current model.

\begin{tabular}{|c|c|c|c|c|c|}
\hline Case & $\beta$ & $\tau$ & $\lambda$ & $Y$ & $R^{2}$ \\
\hline \multirow{3}{*}{ (a) } & \multirow{3}{*}{0} & \multirow{3}{*}{4} & \multirow{3}{*}{5.12} & 0.025 & 0.906487849 \\
\hline & & & & 0.25 & 0.910631403 \\
\hline & & & & 0.475 & 0.914969083 \\
\hline \multirow{3}{*}{ (b) } & \multirow{3}{*}{0} & \multirow{3}{*}{30} & \multirow{3}{*}{1.07} & 0.025 & 0.931204774 \\
\hline & & & & 0.25 & 0.95034509 \\
\hline & & & & 0.475 & 0.931461486 \\
\hline \multirow{3}{*}{ (c) } & \multirow{3}{*}{20} & \multirow{3}{*}{6} & \multirow{3}{*}{2.36} & 0.025 & 0.87950731 \\
\hline & & & & 0.25 & 0.884024739 \\
\hline & & & & 0.475 & 0.951144181 \\
\hline \multirow{3}{*}{ (d) } & \multirow{3}{*}{20} & \multirow{3}{*}{9} & \multirow{3}{*}{0.95} & 0.025 & 0.906989641 \\
\hline & & & & 0.25 & 0.927093896 \\
\hline & & & & 0.475 & 0.853750853 \\
\hline \multirow{3}{*}{ (e) } & \multirow{3}{*}{40} & \multirow{3}{*}{12} & \multirow{3}{*}{4.88} & 0.025 & 0.871029 \\
\hline & & & & 0.25 & 0.981109 \\
\hline & & & & 0.475 & 0.938936 \\
\hline \multirow{3}{*}{ (f) } & \multirow{3}{*}{40} & \multirow{3}{*}{24} & \multirow{3}{*}{2.46} & 0.025 & 0.813929407 \\
\hline & & & & 0.25 & 0.97548186 \\
\hline & & & & 0.475 & 0.82164695 \\
\hline
\end{tabular}

dynamic pressure distribution is calculated while, the effect of transom stern and pressure alleviation when getting closer to the chine are taken into account. Therefore, (19) and (20) are used for calculation of hydrostatic pressure at any given point and consequently the total pressure would be the sum of both pressures calculated so far. This type of modeling can only give the dynamic or the total pressure acting on the planing hull which can then be used to evaluate the 3dimensional pressure distribution. The parameters used as input for calculations are deadrise angle, trim angle, averaged wetted length, and velocity coefficient (transverse Froude number). In the case of only modeling the dynamic pressure, the transverse Froude number is not required as an input.

A computer code is developed which uses two computational loops as illustrated in Figure 9. In the first loop, calculations are performed with the alteration of $Y$, while the second loop changes the value of $X$ in order to achieve a fully expanded calculation over the bottom of the planing hull. The value of $X$ (nondimensional distance from the stagnation line) is set to be positive in all equations and is only set as negative for representations in various figures. The reason for the value of $X$ extending from 0 to $\lambda_{Y}$ at each longitudinal section can be sought in the fact that at each section, the pressure changes are calculated from the stagnation point up to the transom stern. The flowchart for the proposed algorithm is shown in Figure 9.

\section{Validation}

Experimental results of Kapryan and Boyd [1] are used in order to validate the obtained results for the longitudinal dynamic pressure distribution. They [1] evaluated the pressure at various longitudinal sections for three different planing hulls with deadrise angles of 0,20 , and 40 at multiple trim angles and averaged wetted lengths. Their experiments were executed at 26 different cases that due to the high volume of results in their study, only two cases for each deadrise angle are chosen for validation purposes. In their experiments [1], parameter $X$ behind the stagnation line has positive values while in the present study this parameter has negative values behind the stagnation line. Therefore, in order to achieve a good comparison, the results of [1] are made negative. Figure 10 shows the comparison between the current results and the experimental results of [1] in different conditions which prove that the proposed mathematical model has favorable accuracy.

In order to further support the accuracy of the obtained results against the experimental data, $R$-squared values of the plots in Figure 10 have been presented in Table 1. The values of $R$-squared have been calculated using equation

$$
R^{2}=1-\frac{S S_{\text {res }}}{S S_{\text {tot }}}
$$

where values of $S S_{\text {res }}$ and $S S_{\text {tot }}$ are obtained using

$$
\begin{gathered}
S S_{\text {res }}=\sum\left(\frac{P}{q}_{\text {Exp }}-\frac{P}{q_{\text {Mean }}}\right)^{2}, \\
S S_{\text {res }}=\sum\left({\frac{P}{q_{\text {Exp }}}}-\frac{P}{q_{\text {Predicted }}}\right)^{2} .
\end{gathered}
$$

Here, $P / q_{\operatorname{Exp}}$ is the measured pressure by Kapryan and Boyd [1] and $P / q_{\text {Mean }}$ is the mean of the measured pressures in each plot. On the other hand, $P / q_{\text {Predicted }}$ is the pressure obtained from the present mathematical model. As evidenced in Table 1 , the $R$-squared values are fairly close to 1.0 , indicating a favorable accuracy of the obtained results.

In order to validate the obtained results for the hydrostatic pressure, the exerted lift force by this pressure calculated from (25) is compared against the hydrostatic lift force coefficient of planing hulls proposed by Savitsky [5]. Accordingly, the hydrostatic pressure acting on the bottom of the planing hull is integrated over a planing plate and can be calculated from (26) as follows:

$$
\begin{gathered}
C_{L 0}=0.0055 \frac{\lambda^{2.5}}{C_{V}^{2}} \tau^{1.1}, \\
C_{L 0}=\int_{-0.5}^{0.5} \int_{0}^{\lambda_{y}} \frac{P_{B}}{q} d x d y \cos \tau .
\end{gathered}
$$

In order to have a comparison for the obtained results from the previous integration, the curves of $C_{L 0} / \tau^{1.1}$ for both methods and at four different transverse Froude numbers are illustrated in Figure 11. As evidenced in this figure, the integration of (26) gives results that are in agreement with the results of (25) that proves the efficiency and accuracy of the present method for calculation of hydrostatic pressure distribution. The results of $R$-squared values of the data in Figure 11 which are presented in Table 2 affirm this claim. 

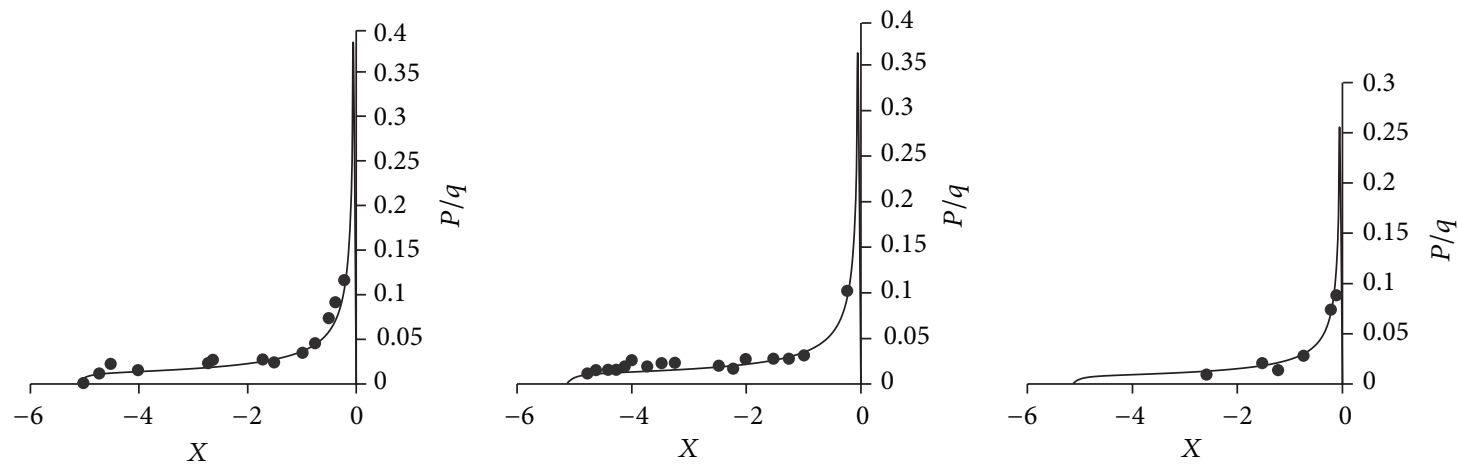

$Y=0.025$

$Y=0.25 \quad \tau=4$

$Y=0.475$

(a)
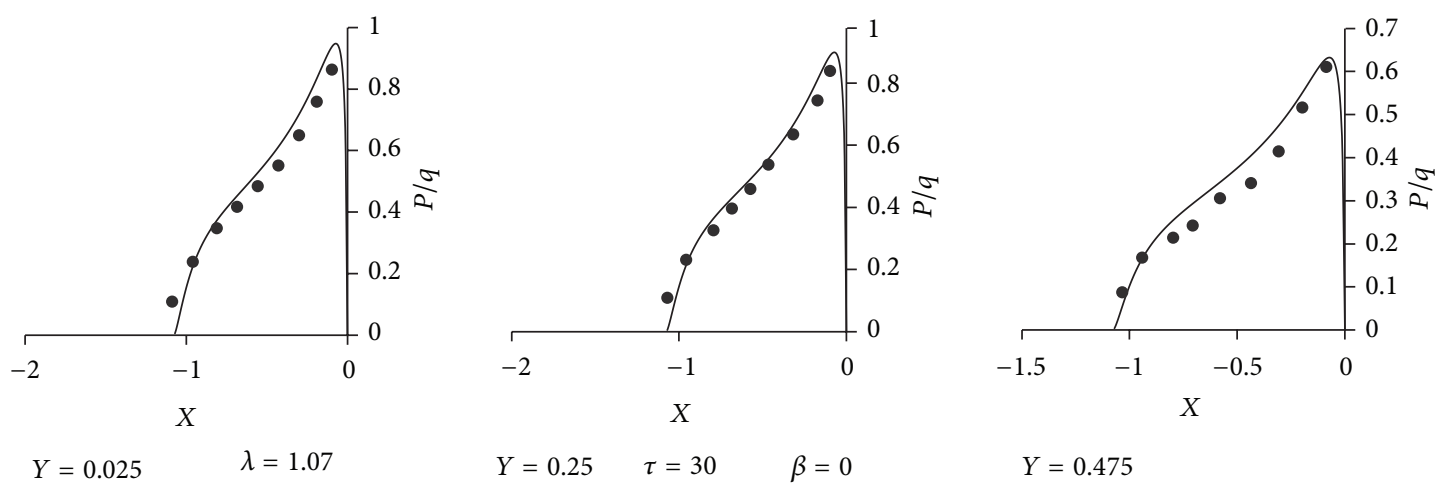

$Y=0.025$

(b)
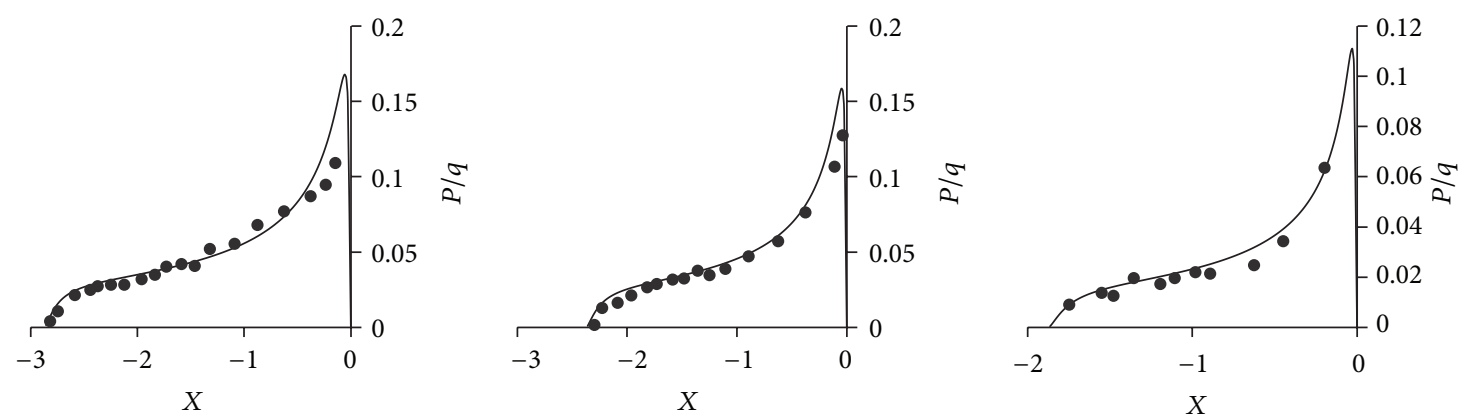

$Y=0.025$

$Y=0.25 \quad \tau=6 \quad \beta=20$

$Y=0.475$

(c)

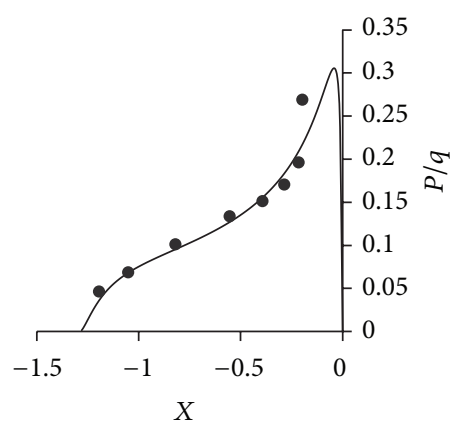

$Y=0.025$

$$
\lambda=0.95
$$

- Mathematical modeling

- $\quad$ Exp Kapryan and Boyd 1955

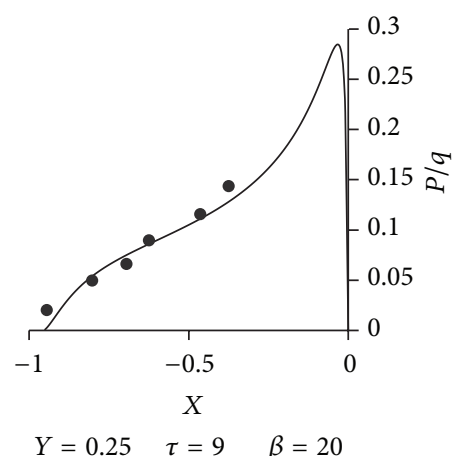

$Y=0.25 \quad \tau=9 \quad \beta=20$

- Mathematical modeling

(d)

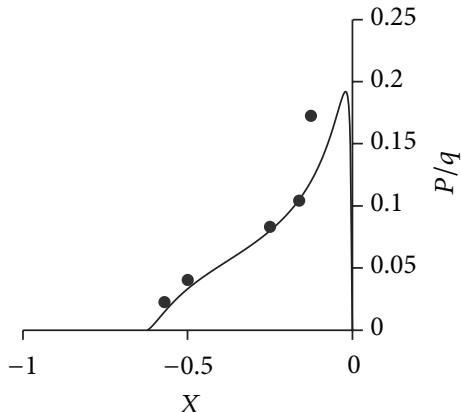

$Y=0.475$

Mathematical modeling

- $\quad$ Exp Kapryan and Boyd 1955

FIGURE 10: Continued. 


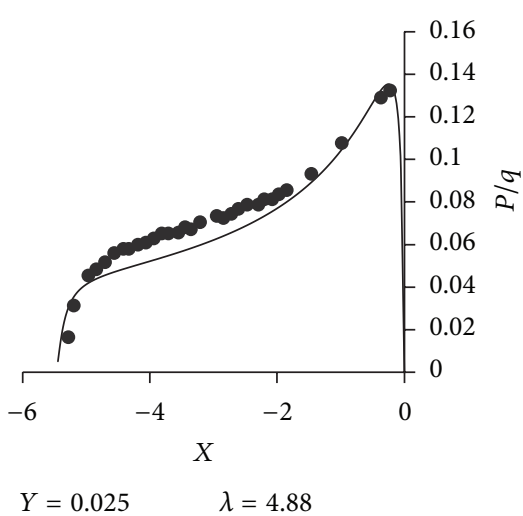

$Y=0.025 \quad \lambda=4.88$

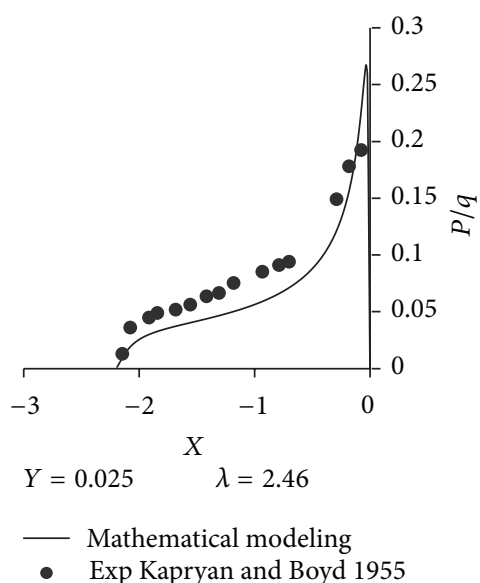

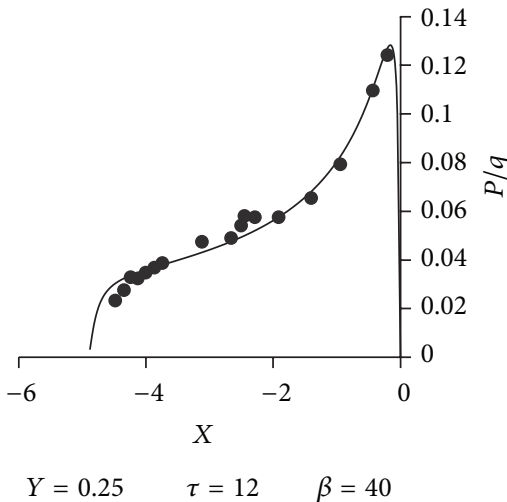

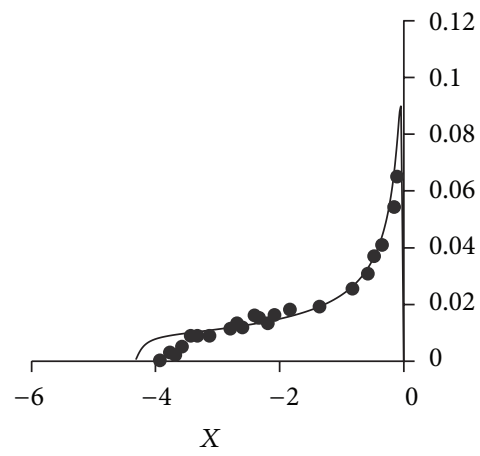

(e)
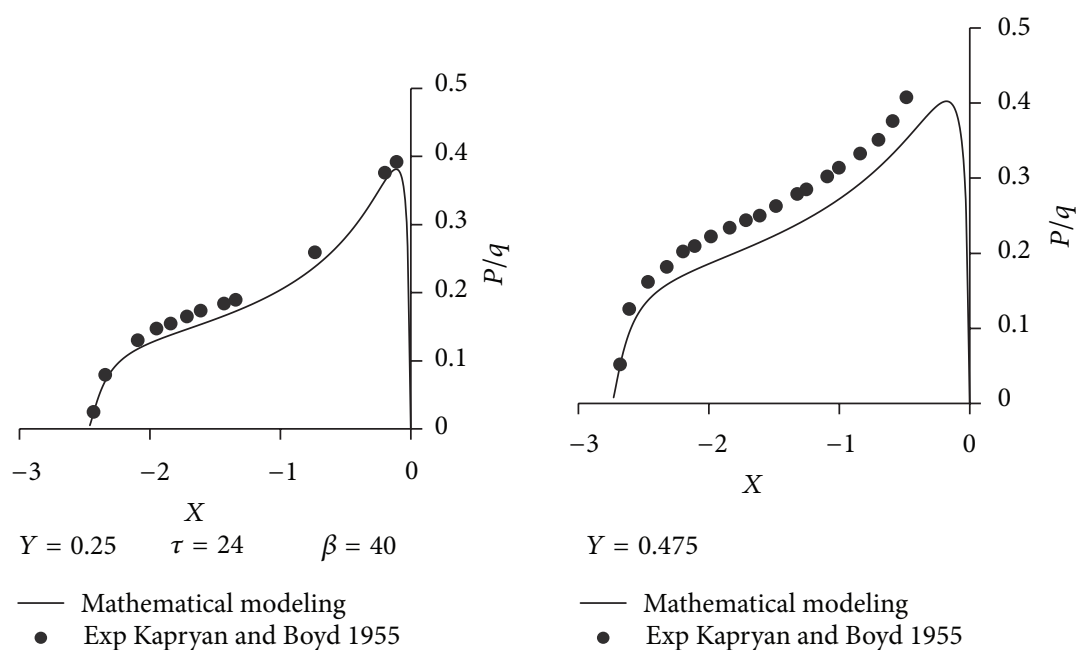

(f)

FIGURE 10: Comparison between the obtained results and the experimental results of Kapryan and Boyd [1] for the validation of dynamic pressure distribution.

TABLE 2: $R$-squared values for hydrostatic lift coefficients on planing hulls.

\begin{tabular}{lcc}
\hline Case & $C_{V}$ & $R^{2}$ \\
\hline (a) & 1 & 0.92417071 \\
(b) & 2 & 0.901327451 \\
(c) & 4 & 0.924163963 \\
(d) & 6 & 0.924163968 \\
\hline
\end{tabular}

\section{Results and Discussion}

The obtained results from the present mathematical modeling are studied as parts of two main categories. In the first category, the 3-dimensional dynamic pressure distribution over planing hull and different parameters affecting it are studied. The total pressure distribution and the effects of different parameters on this distribution are studied in the second category.

4.1. Dynamic Pressure. Based on the present mathematical method, the 3-dimensional dynamic pressure distribution on planing hulls is modeled. Afterwards, the effect of trim angle, deadrise angle, and averaged wetted length on this distribution is studied.

4.1.1. The Effect of Trim and Deadrise Angles. In order to study the effect of trim and deadrise angles on the 3dimensional dynamic pressure distribution, the modeling has been accomplished at different angles with a fixed wetted length. The obtained results are shown in Figures 12, 13, 14, and 15 . As seen in these figures, the increase of trim angle at a fixed deadrise angle causes the maximum pressure, pressure distribution, and pressure level to rise which leads to an increase in hydrodynamic lift force. Moreover, increase of deadrise angle at a fixed trim angle causes the maximum pressure and pressure level to alleviate and subsequently decreases the hydrodynamic lift force. The effect of deadrise angle on the maximum pressure subsides with an increase of the trim angle.

4.1.2. The Effect of Wetted Length. In order to study the effect of the averaged wetted length on 3-dimensional dynamic 


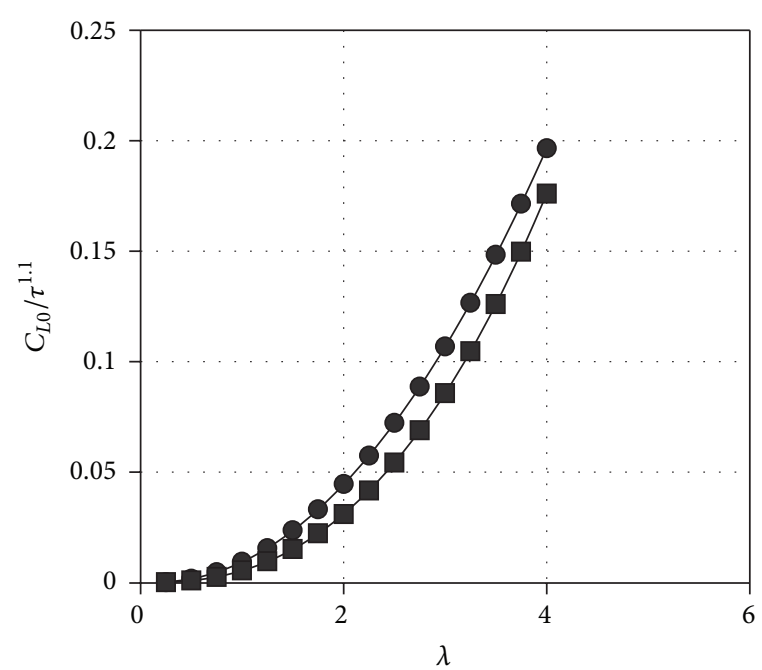

(a) $C_{V}=1$

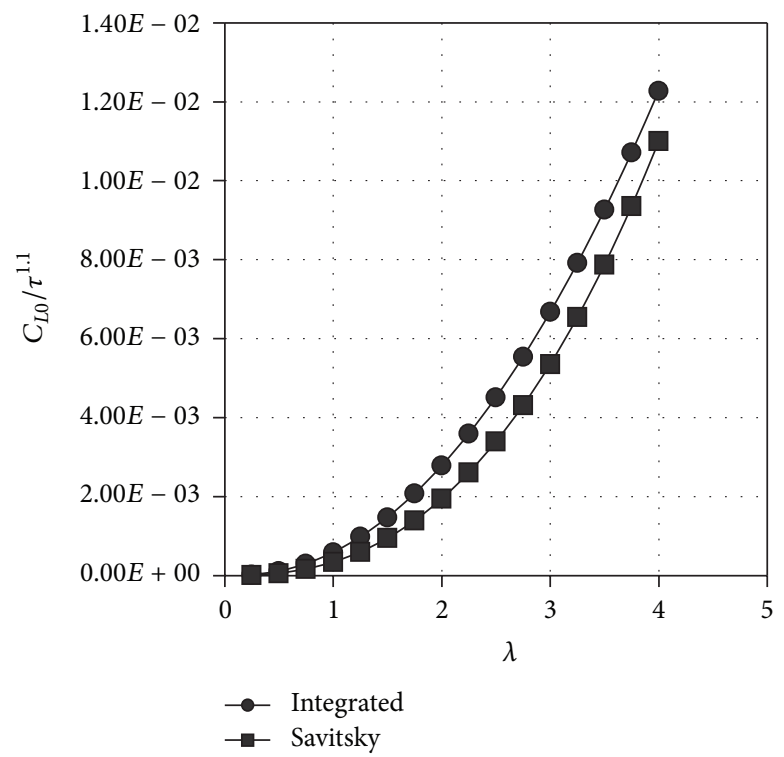

(c) $C_{V}=4$

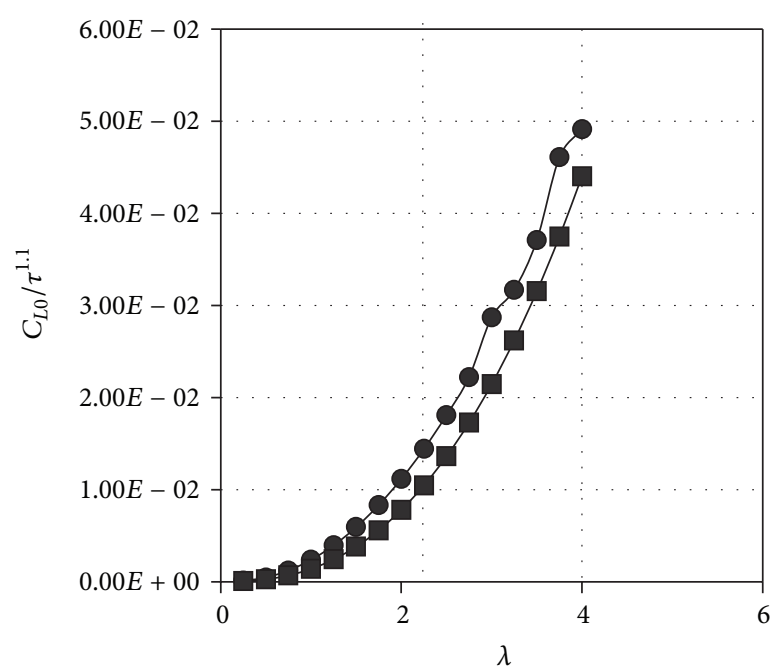

(b) $C_{V}=2$

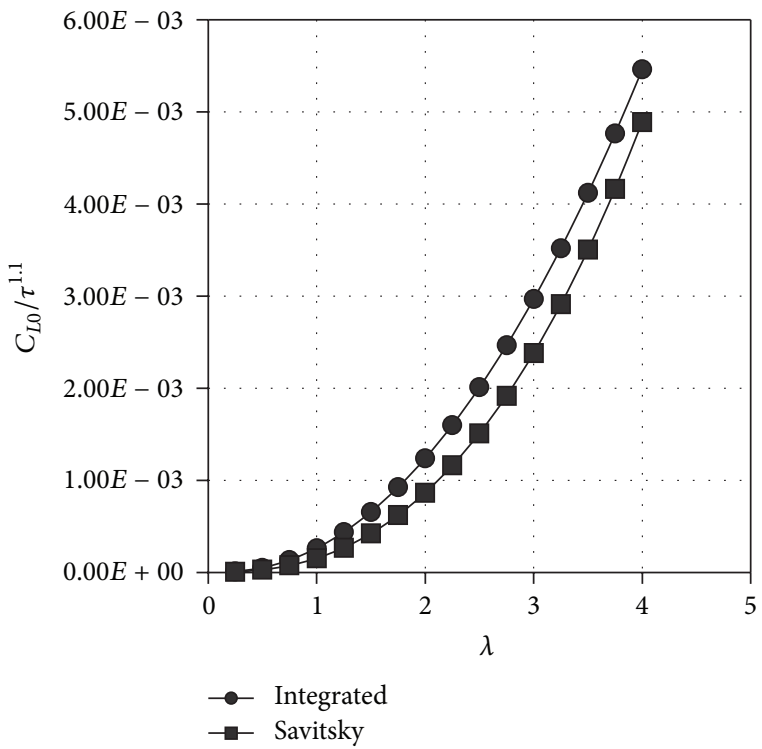

(d) $C_{V}=6$

FIGURE 11: Comparison between the hydrostatic lift force coefficients on planing plate calculated using the proposed integration method and the equation of [5].

pressure distribution over a planing hull, a body with constant deadrise and trim angle is studied. It has been seen that an increase in wetted length causes the pressure level to rise, but has no effect on the pressure distribution and the obtained maximum pressure (see Figure 16).

4.2. Total Pressure. The sum of dynamic and hydrostatic pressures at any given point gives the total pressure. Therefore, the present method is able to model the 3-dimensional total pressure distribution on the planing hull. As a result, the effect of the velocity coefficient on the total pressure distribution is studied. As clearly seen in Figure 15, at a constant trim angle, deadrise angle, and averaged wetted length, an increase in velocity coefficient leads to a decrease in hydrostatic pressure and consequently a decrease in total pressure which will result in a reduction of total lift force (see Figure 17).

\section{Conclusion}

In this article, three-dimensional mathematical modeling of dynamic and total pressure distribution over a planing hull is presented and the obtained results are validated against experimental results. The calculated $R$-squared values of the corresponding data, which are relatively close to 1.0 , indicate that the proposed method has favorable accuracy and efficiency. Moreover, the accuracy of the present model in determination of the hydrostatic pressure distribution is shown to be favorable in comparison with the hydrostatic term in the lift force coefficient equation. This claim is also 


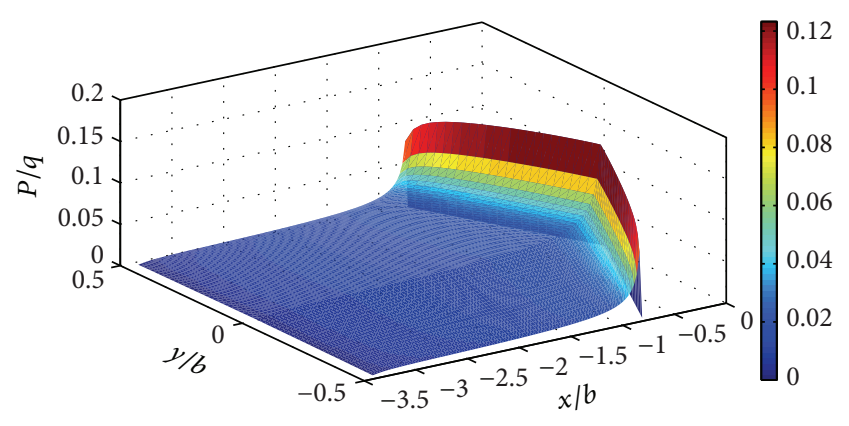

(a) $\tau=2$

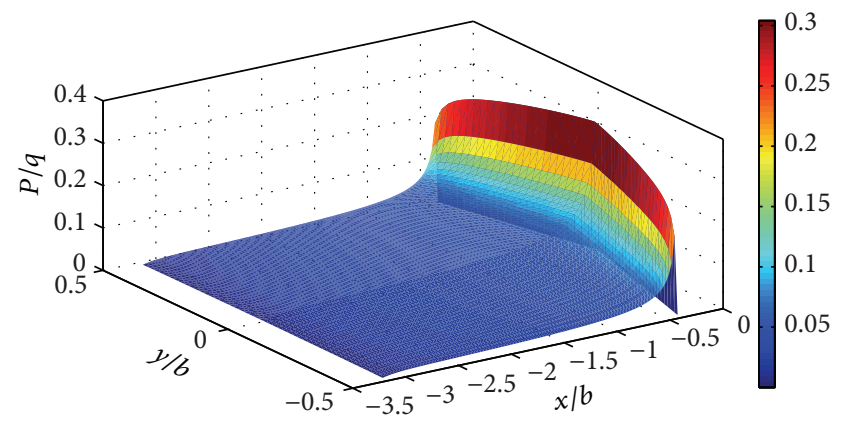

(b) $\tau=4$

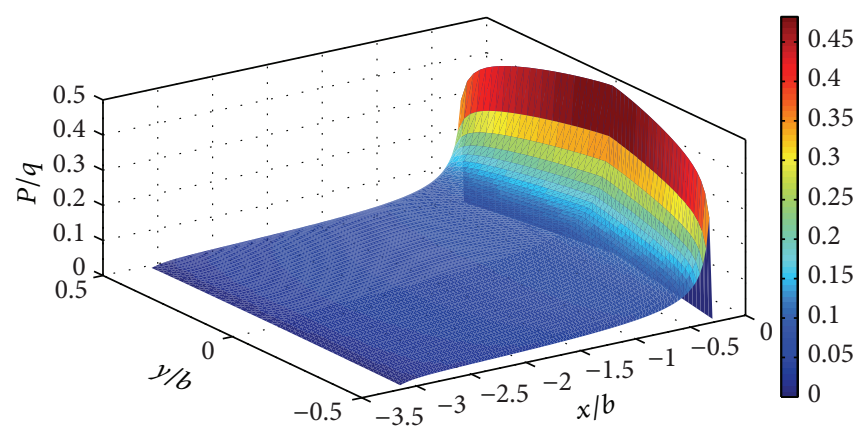

(c) $\tau=6$

FIgURE 12: Three-dimensional pressure distribution over planing hull for $\beta=5$ and $\lambda=3$.

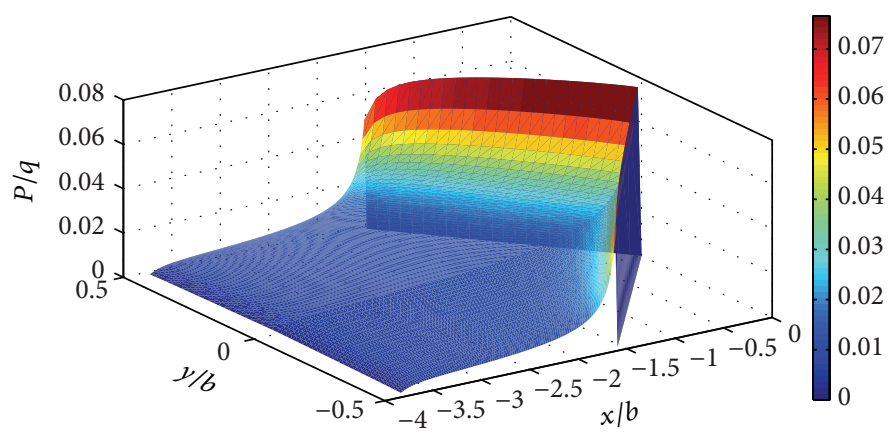

(a) $\tau=2$

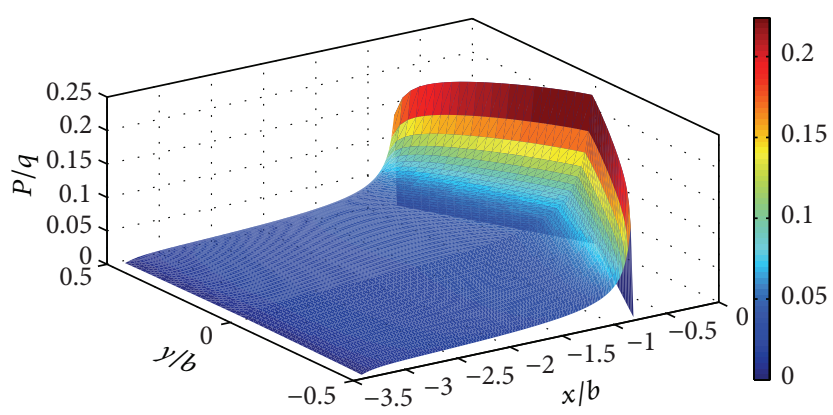

(b) $\tau=4$

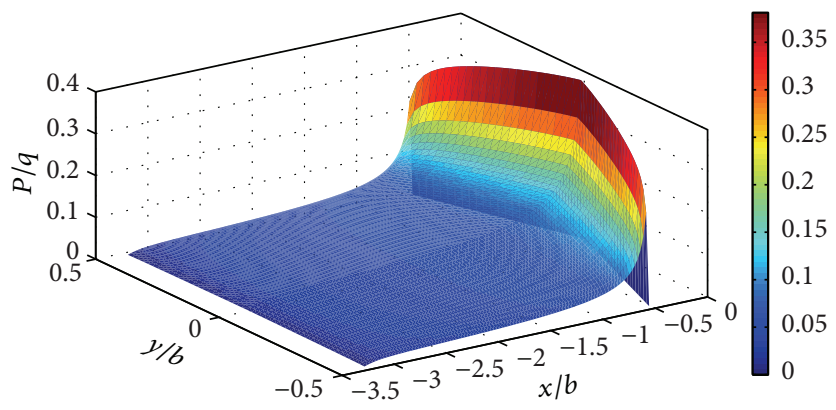

(c) $\tau=6$

FIGURE 13: Three-dimensional pressure distribution over planing hull for $\beta=10$ and $\lambda=3$. 


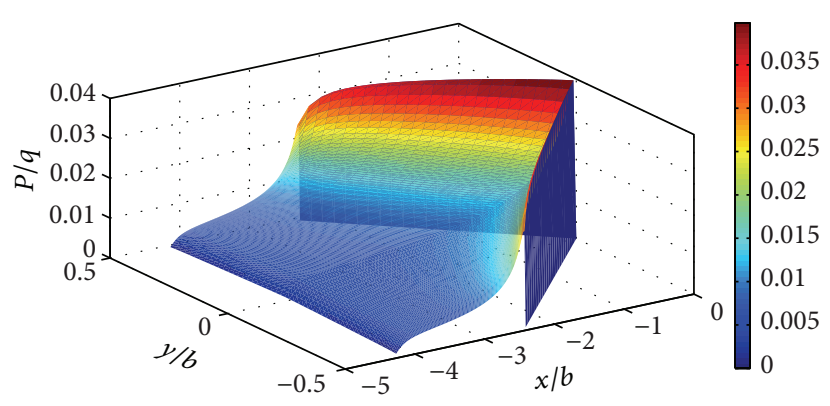

(a) $\tau=2$

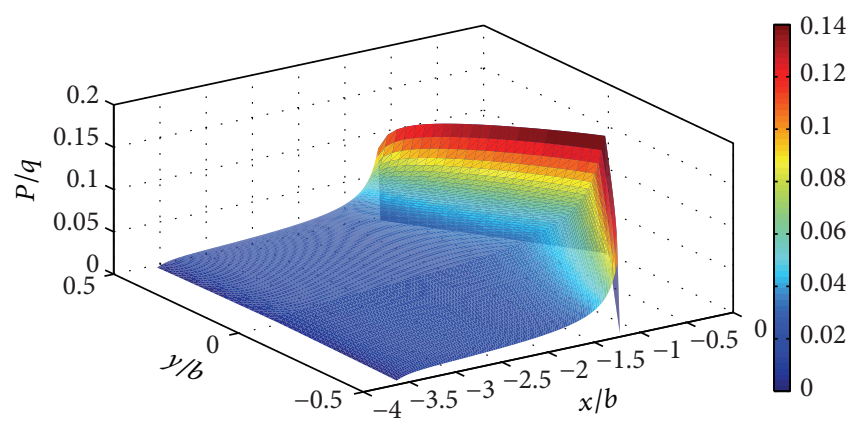

(b) $\tau=4$

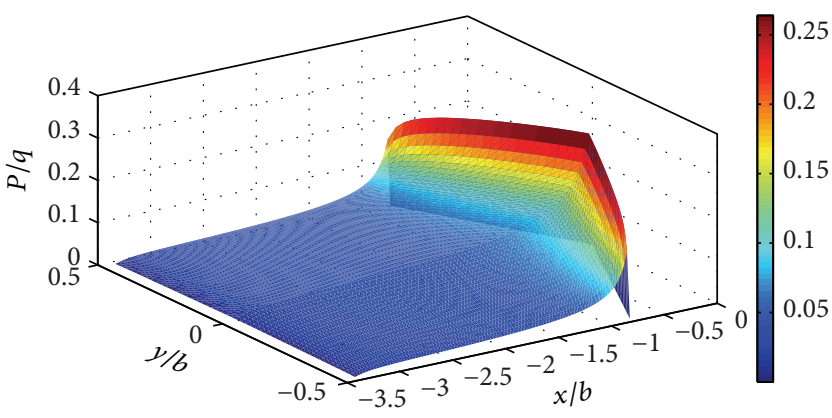

(c) $\tau=6$

FIGURE 14: Three-dimensional pressure distribution over planing hull for $\beta=15$ and $\lambda=3$.

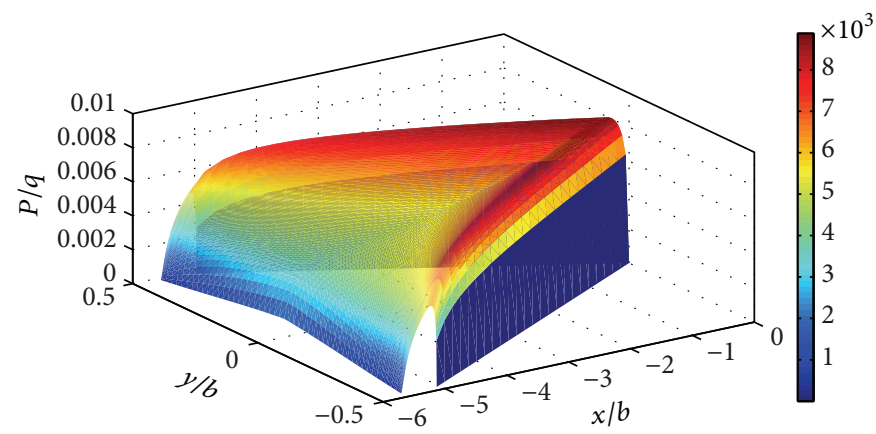

(a) $\tau=2$

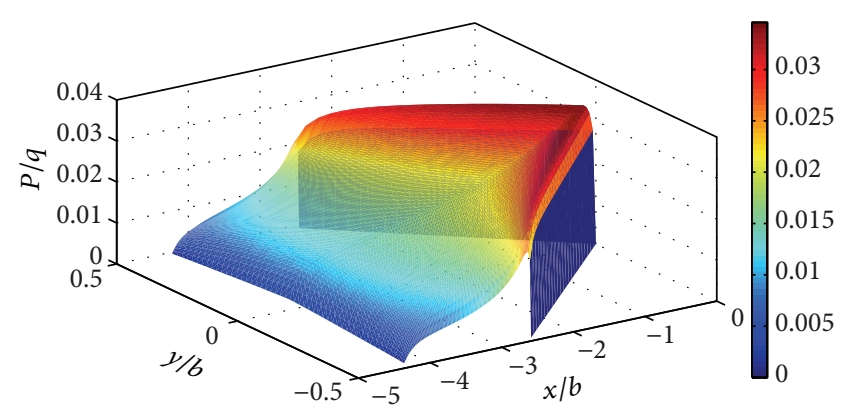

(b) $\tau=4$

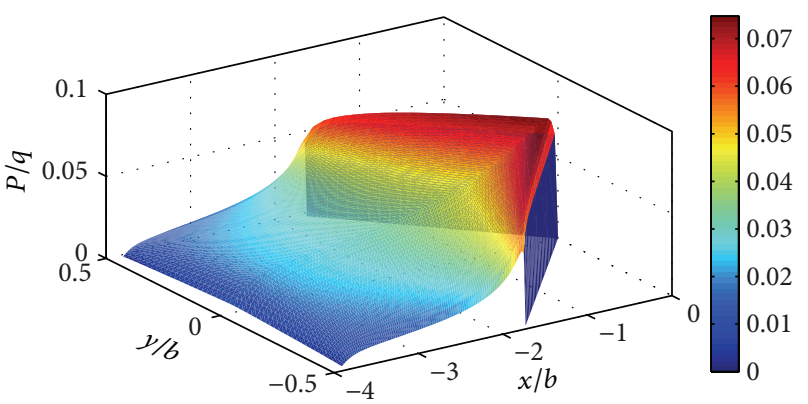

(c) $\tau=6$

FIGURE 15: Three-dimensional pressure distribution over planing hull for $\beta=30$ and $\lambda=3$. 


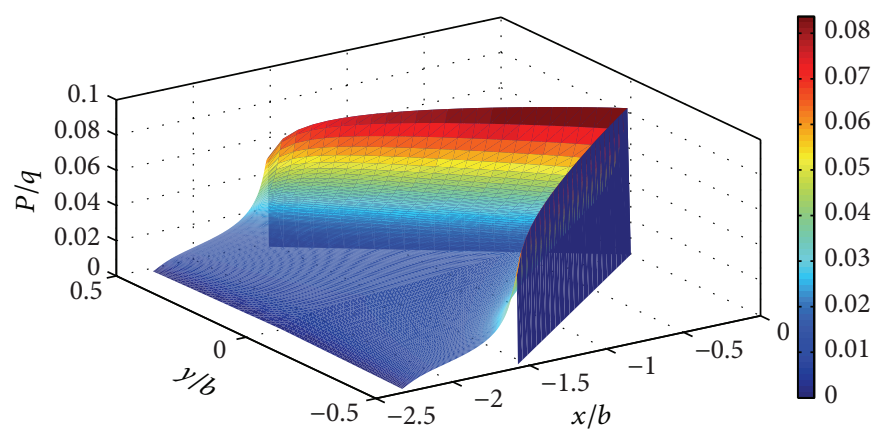

(a) $\lambda=1.5$

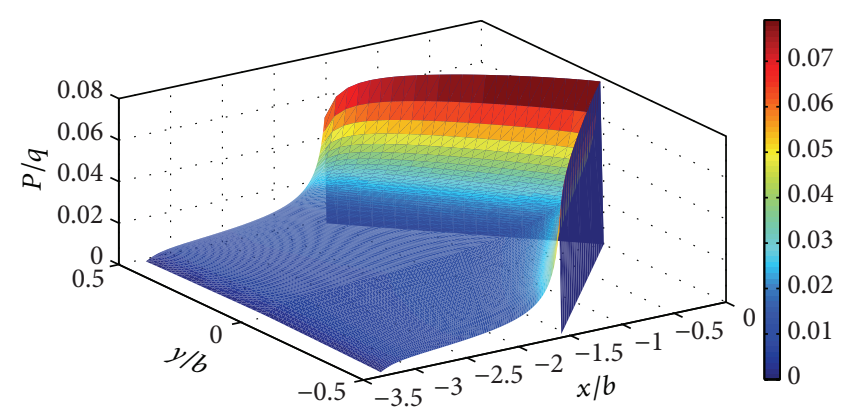

(b) $\lambda=2.5$

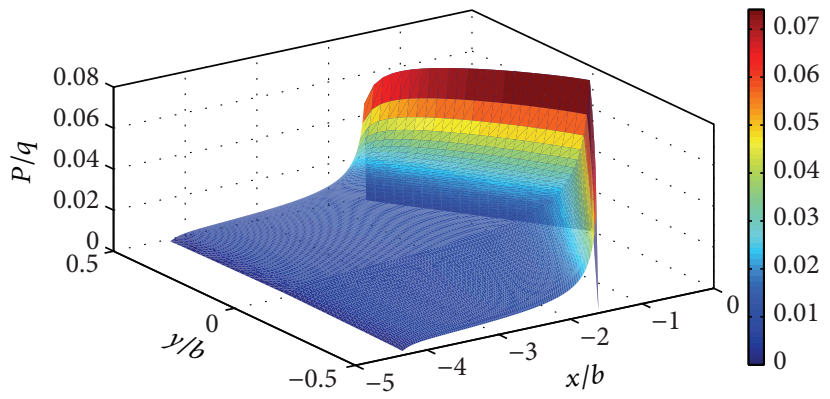

(c) $\lambda=3.5$

FIGURE 16: The effect of averaged-wetted length on 3-dimensional dynamic pressure distribution for a planing hull with $\tau=2$ and $\beta=10$.

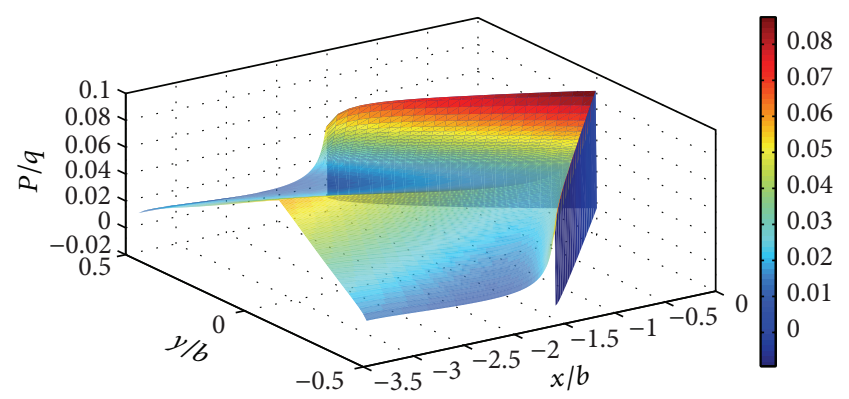

(a) $C_{V}=2$

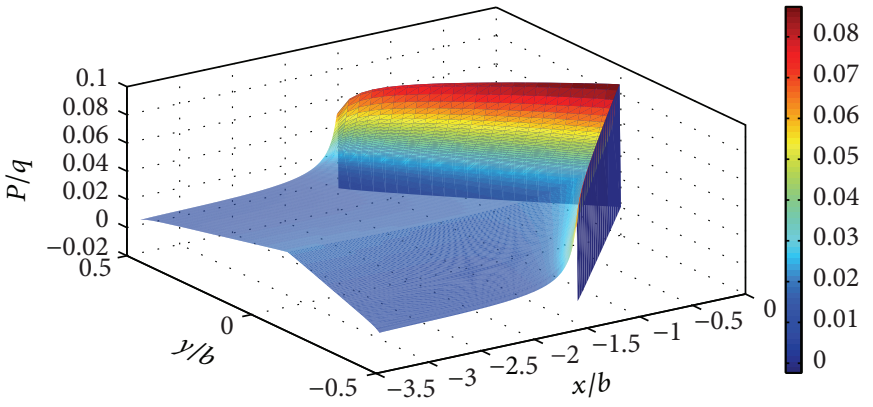

(b) $C_{V}=4$

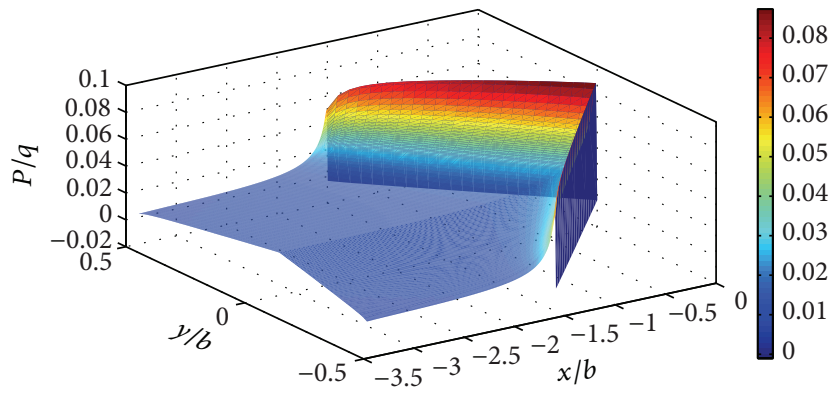

(c) $C_{V}=6$

FIGURE 17: The effect of velocity coefficient on 3-dimensional total pressure distribution on a planing hull with $\tau=2$ and $\beta=15$.

corroborated by its suitable $R$-squared values. Mathematical equations used in the present study take into account the effect of transom stern and chine on dynamic and hydrostatic pressure distributions. Using the proposed algorithm, 3dimensional pressure distribution over the bottom of a planing plate is calculated.
The effect of trim angle on the increase of pressure values and pressure level and the effect of deadrise angle on the reduction of these values are presented. As seen in Figure 12 through Figure 15, at a constant trim angle and averaged wetted length, the effect of deadrise angle is studied, while the effect of trim angle is similarly analyzed with 
a constant deadrise and averaged wetted length. Furthermore, the independence of pressure distribution from the averaged wetted length is studied through various computational tests which show that the pressure distribution and consequently lift force are increased. Finally, the hydrostatic pressure alleviation and subsequently the decrease in total pressure acting on a planing plate are studied for an increase of the velocity coefficient.

Study of lift force, center of pressure, and influential parameters for V-bottom hull forms and the pressure distribution on asymmetric planing catamaran demihulls and trimarans using empirical equations can be the subject of future studies.

\section{References}

[1] W. J. Kapryan and G. M. Boyd, "Hydrodynamic pressure distribution obtained during a planing investigation of five related prismatic surfaces," NACA Technical Note, 1955.

[2] R. F. Smiley, "A study of water pressure distribution during landing with special reference to a prismatic model having a heavy loading and a 30-degree angle of deadrise," NACA Translation, 1950.

[3] R. F. Smiley, "An experimental study of the water-pressure distributions during landing and planing of a heavily loaded rectangular flat-plate model," NACA Technical Note 2453, 1951.

[4] H. Wagner, "Phenomena associated with impacts and sliding on liquid surfaces," NACA Translation, 1932.

[5] D. Savitsky, Hydrodynamic Design of Planing Hulls, vol. 1, Marine Technology, 1964.

[6] J. F. Wellicome and Y. M. Jahangeer, "The prediction of pressure loads on planing hulls in calm water," Royal Institution of Naval Architects, no. 2, pp. 53-70, 1978.

[7] P. Ghadimi, A. Dashtimanesh, M. Farsi, and S. Najafi, "Investigation of free surface flow generated by a planing flat plate using smoothed particle hydrodynamics method and FLOW3D simulations," Journal of Engineering Maritime Environment, 2012.

[8] D. Savitsky, M. F. DeLorme, and R. Datla, "Inclusion of whisker spray drag in performance prediction method for high-speed planing hulls," Marine Technology, vol. 44, no. 1, pp. 35-56, 2007.

[9] M. G. Morabito, On the spray and bottom pressures of planing surfaces [Ph.D. thesis], Stevens Institute of Technology, 2010.

[10] W. Sottorf, "Experiments with planing surfaces," NACA Translation, 1934.

[11] J. D. Pierson and S. Leshnover, "A study of the flow, pressure and loads pertaining to prismatic vee-planing surfaces," Report SIT DL 50382, Davison Laboratory, 1950.

[12] B. V. Korvin-Kroukovsky and F. R. Cahbrow, "The discontinuous fluid flow past an immersed wedge," S.M.F Fund Paper 167, Institute of Aeronautical Science, 1948.

[13] M. White Frank, Fluid Mechanics, chapter 2, McGrowHill, 4th edition, 1998.

[14] C. L. Shuford, "A theoretical and experimental study of planing surfaces including effects of cross section and plan form," NACA Technical Note 3939, 1957. 

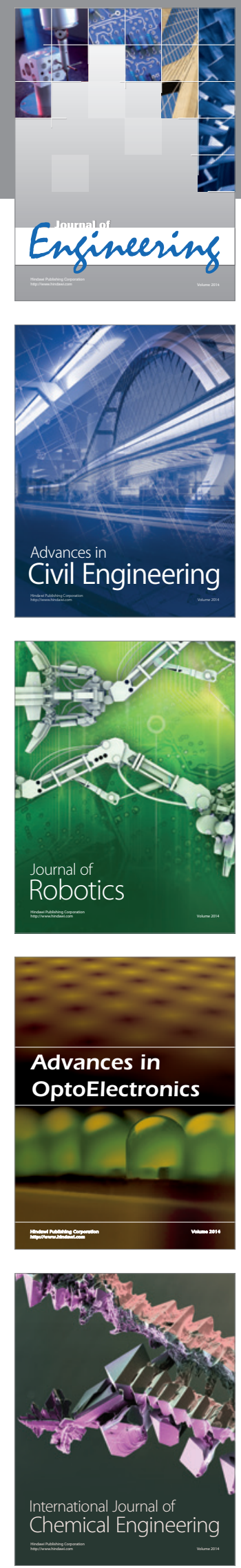

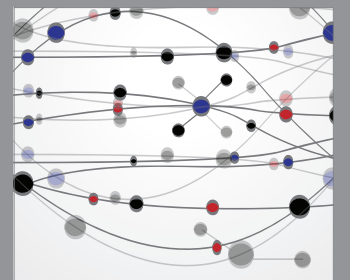

The Scientific World Journal
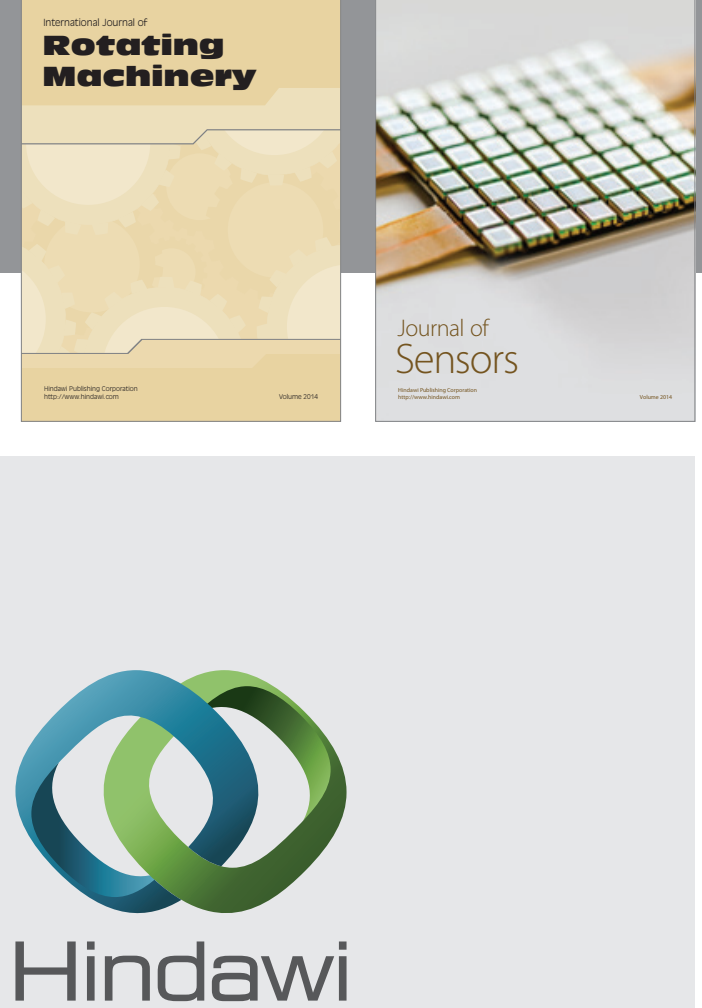

Submit your manuscripts at http://www.hindawi.com
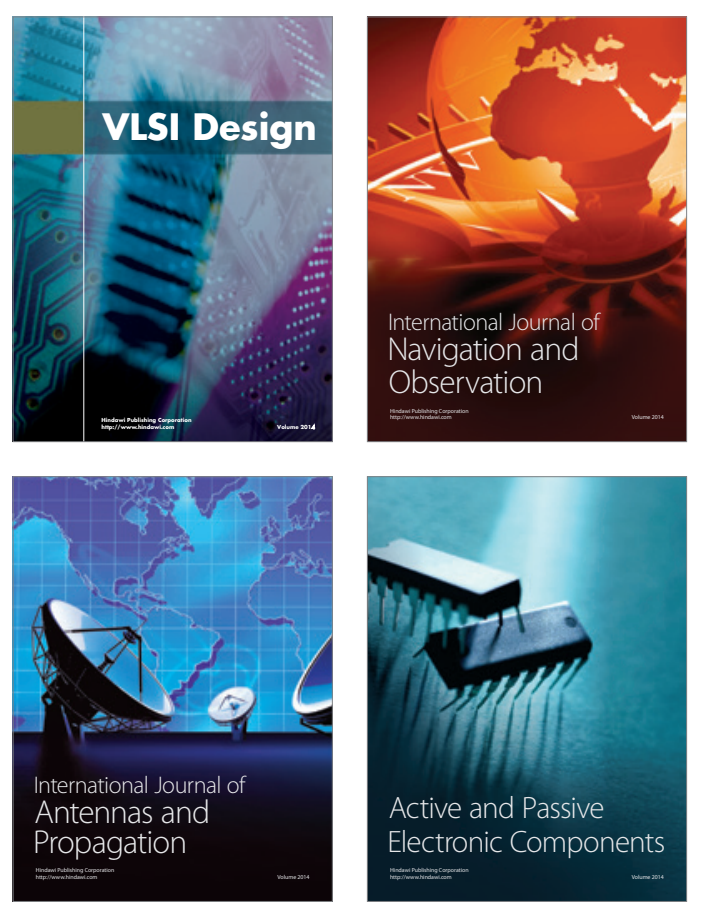
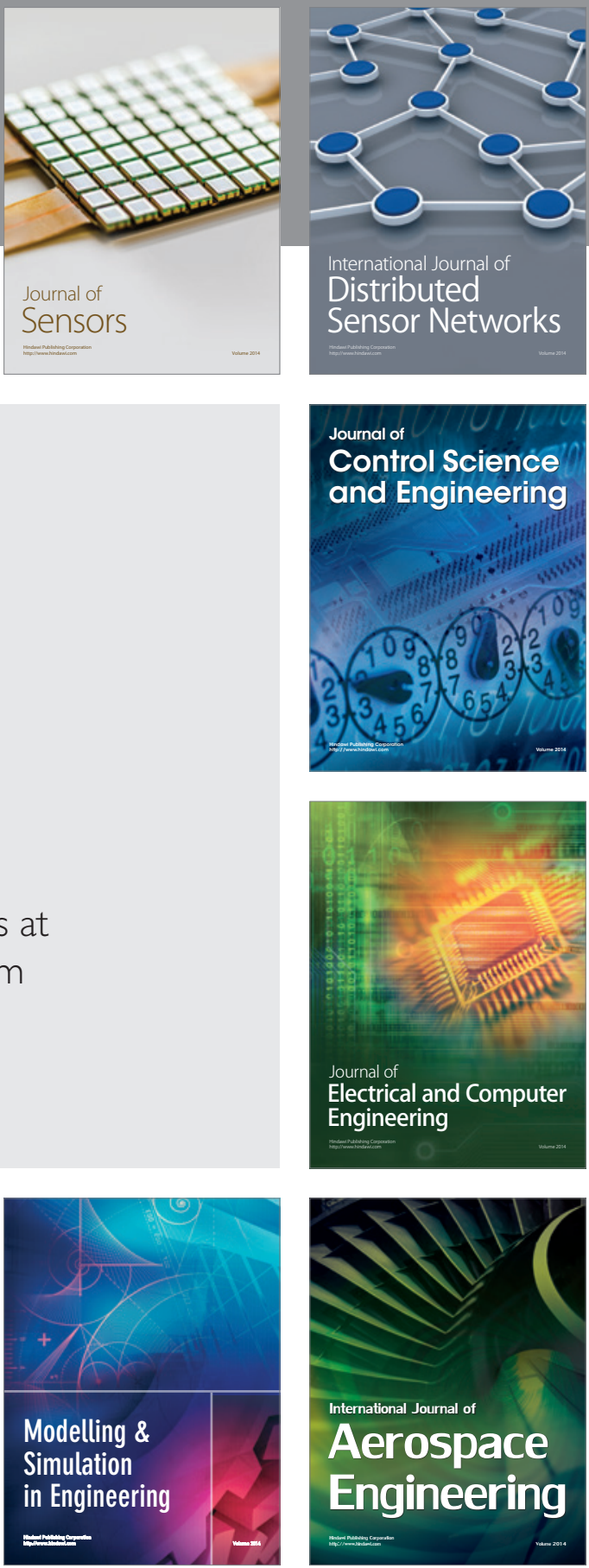

Journal of

Control Science

and Engineering
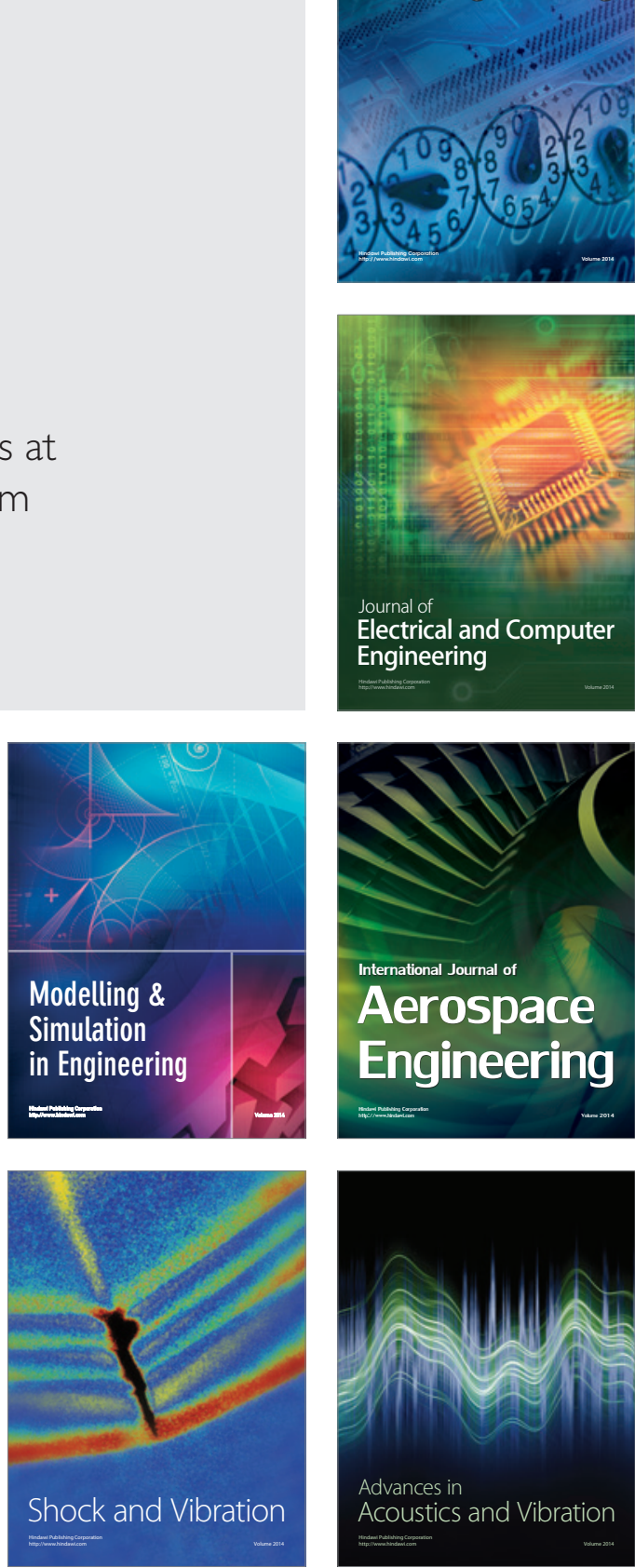